Томас Брунс

Германия, Трирский университет

\title{
Пунктуационные знаки и смайлики - объединяющие и разделяющие функции в цифровой коммуникации
}

Ключевые слова: пунктуационный знак, эмотикон, смайлик, эмодзи, цифровая коммуникация.

Key words: punctuation mark, smiley, emoticon, emoji, digital communication.

\section{Abstract}

This article aims to give an overview of similarities and differences in the function and use of smileys and emojis on the one hand and punctuation marks on the other hand in digital communication. It becomes clear that the traditional punctuation marks in their current use and the relatively new graphic symbols used in chats, messengers and forums are not so different at all, but show certain similarities, in that they can supplement, modify or even completely replace the written message itself.

За последние тысячелетия система человеческого языка претерпела множество глубоких изменений. Из первичной оральности развилась письменная культура с последовательным и частично параллельным применением различных алфавитов. В обществах, доминированных латинской и греческой культурами, более 2000 лет назад были изобретены и интегрированы в письменную систему дополнительные графические символы с структурирующими и - в ограниченной степени - значимыми функциями: знаки препинания. Здесь нет места в детали излагать историю этих пунктуационных знаков. Достаточно сказать, что этот перечень постепенно расширялся, изменялся и уточнялся и по сей день. Многие из этих изменений были сделаны сознательно, спланированы, а иногда и под давлением правителей и их советников. Затем цифровая революция коснулась и сферы человеческой коммуникации, и у многих наблюдателей и участников этого процесса сложилось впечатление, что коммуникация постепенно теряет свою нормированность. Правила правописания и пунктуации, как представляется, больше не применяются в значительной части цифровой коммуникации, или, что еще хуже, интерпретируются по-новому, что приводит к искажениям 
между сферами использования (цифровое и нецифровое, общественное и (псевдо)частное пространства) и вызывает путаницу. Кроме того, уже несколько лет существует новая система графических знаков, которые можно охарактеризовать как паралингвистические: смайлики и эмотиконы. Некоторые из них выполняют замещающую функцию, поскольку могут использоваться вместо лингвистических знаков; другие имеют эффект металингвистического комментария, поскольку они могут дополнять, нюансировать и оценивать лингвистический контент. Таким образом, они, по крайней мере частично, берут на себя роль интонации в разговорном языке. В предлагаемой работе рассматривается функция цифровой пунктуации при взаимодействии с эмотиконами и смайликами в рамках их общего аспекта расширения графического инвентаря данного языка.

До конца XX в. перечень языковых символов состоял из букв и знаков препинания, а также других символов, используемых в письменной форме. Последние служили и продолжают служить типографским целям, а также используются в самых разнообразных областях (естественных) наук. В принципе, эти три группы символов образуют гомогенное целое в рамках письменной культуры конкретного общества, но на протяжении веков и тысячелетий они претерпевали изменения. Некоторые из них были такими дальнобойными, что они не могут быть здесь подробно описаны. Последним - и ограниченным цифровой сферой - шагом в развитии человеческой коммуникации до сих пор являются внедрение и ныне массовое использование смайликов.

Таким образом, письменная коммуникация в цифровом виде использует, независимо от конкретного, отдельного языка, широкий спектр различных типов символов: буквы (графемы) - знаки препинания ${ }^{1}$ - типографские символы $(@, \#)$ - гибридные графические изображения, состоящие из знаков препинания и типографских символов (эмотиконы) - гибридные последовательности символов, состоящие из букв и цифр (символослова) $)^{2}$ - аббревиатуры (LOL, IMНО, ИМХО) - смайлики/эмодзи ${ }^{3}$.

Археологии, этнологии и смежным областям науки удалось доказать, что первые письменные знаки, произведенные человеком, намного моложе старших

1 В русском языке по обыкновению разграничивают следующие 10 пунктуационных знаков: точку, вопросительный знак, восклицательный знак (в качестве знаков конца предложения), запятую, тире, двоеточие, точку с запятой (как знаки разделения частей предложения), скобки, кавычки (как «двойные» знаки, выделяющие отдельные слова или части предложения) и носящее особое смысловое значение многоточие. К ним добавляются такие знаки, как косая черта (слэш/слеш), обратная косая черта (бэкслэш/ бэкслеш) и др., имеющие специфические функции именно в цифровом общении.

2 GOST R 51725.17.1-2016 определяет термин символослово как: «Слово, включающее словесный знак и символы (цифры, буквы, графические знаки)» (cp. http://docs.cntd. $\mathrm{ru} /$ document/1200138355; 8.04.2020).

3 «[...] смайликом мы называем значки с лицами, выражающие разные эмоции, а среди эмодзи можно найти любые рисунки, например, автомобили, природу, людей, еду» [Priroda èmodzi 2016]. С 2011 г. эмодзи вошли в состав стандартизованного Юникода 6.0. 
свидетельств в образном виде (изображения зверей, сцен охоты, частей человеческого тела). Интересно, что новейший элемент в межличностном общении снова состоит из картинных элементов, а именно смайликов или эмодзи. Между древнейшими и новейшими пикторальными формами - тысячелетняя, чрезвычайно разнообразная письменная традиция, которая, в зависимости от отдельной культуры, в той или иной степени сочетала и дополняла письменную систему пиктографическими формами искусства. В качестве таких форм можно привести средневековые рукописи с их художественными миниатюрами. Напротив, современные, сгенерированные компьютером миниатюрные изображения смайликов и эмодзи могут показаться банальными и весьма простыми. Их ценность заключается не столько во внешнем виде, сколько в функциональности. В отличие от средневековых декоративных рукописей, которые все были уникальны, компьютерная графика может воспроизводиться бесконечно, с бешеной скоростью и в неизменном качестве, что делает их пригодными для массового использования. Нередко инфляционное использование этих коммуникационных элементов в очередной раз произвело революцию в нашем способе обмена информацией. Скептики даже боятся, не без оснований, что эмотиконы и эмодзи отчасти заменят письменный язык в определенных цифровых каналах связи. В статье «Priroda èmodzi» [2016] цитируются слова Президента Оксфордского словаря Каспера Грейтвола, который придерживается мнения, что

«[н]еспособность языка без обращения к дополнительным средствам соответствовать запросам современной цифровой коммуникации 21-ого века ведет к большим переменам». Что касается упомянутых больших перемен, то Грейтвол бессомненно прав. Уже другой вопрос, нуждается ли наш современный язык действительно в такой массе дополнительных коммуникативных средств. Нередко выдвигается мнение, что «в цифровом мире теперь проще высказать свои мысли с помощью эмодзи, нежели словами» [Priroda èmodzi 2016].

В этом отношении знаки препинания с их давней традицией и эмодзи, появившиеся только в 1998-1999 гг., на первый взгляд, имеют мало общего. Несмотря на это, изобретение и непрерывное развитие знаков препинания также глубоко изменило письменную коммуникацию, открыв новые возможности и придав ей новые качества. Последний аспект относится также к эмодзи и связанным с ними формам представления, которые дополняют языковой знак, могут его модифицировать и фактически, в определенной степени и в определенных коммуникационных ситуациях, его заменять. Как наши предки относились к вновь введенным знакам препинания, неизвестно в деталях. Однако можно предположить, что всегда были сторонники и противники нововведений в систему человеческого (письменного) языка. Сегодня эта ситуация ничем не отличается от прошлой. В то время, как особенно молодые люди быстро осознали преимущества эмотиконов и эмодзи, людям старшего поколения, выросшим с другой традицией, естественно, труднее принять такие новшества, а иногда они их отвергают полностью. 
Еще одной параллелью между знаками препинания и эмодзи является повышение визуального характера письменного общения. Использование пунктуационных знаков растворяет континуум расположенных в ряд букв и разделяет его на визуально отличные, отдельные разделы, каждый из которых имеет смысл сам по себе. Кроме того, во многих системах письма различают заглавные и строчные буквы; см., в качестве знакового континуума, следующую последовательность символов:

карточнаяиграобманщикрассчитанана34игроковкоторымпредстоитрассказыватьдругдругунебылицыогерояхизображенныхнакартаховедьмахдраконахпривиденияхинопланетянахиснежномчеловеке

- и та же последовательность символов в качестве визуально, синтаксически и семантически структурированного высказывания:

Карточная игра «Обманщик» рассчитана на 3-4 игроков, которым предстоит рассказывать друг другу небылицы о героях, изображенных на картах - о ведьмах, драконах, привидениях, инопланетянах и снежном человеке [http://www.igry-pochemuchek.ru/ product/nastol_nye_igry_dlja_vsej_sem_i $32019 ; 7.04 .2020]$.

Такая визуальная структура облегчает понимание содержания высказывания и, следовательно, коммуникации. В то же время знаки препинания добавляют свои собственные словесные и/или паравербальные компоненты смысла, ср.: Он тебя обманул. - Он тебя обманул! - Он тебя обманул!!! - Он тебя обманул? Та же самая последовательность букв получает, посредством конечного знака препинания, специфическое выразительное значение либо высказывания, либо восклицания, либо убедительного восклицания, либо вопроса.

В цифровом общении, в чате, в мессенджере или на форуме одна и та же последовательность символов могла бы быть дополнена или закончена различными эмодзи, получая, таким образом, новые толкования. Ср.:

высказывание

\begin{tabular}{ll}
\hline Он тебя обманул & $\begin{array}{l}\text { нейтральное заявление без стилистических или } \\
\text { касающихс содержимого «комментариев» }\end{array}$ \\
\hline Он тебя обманул & $\begin{array}{l}\text { вдумчивость; как такое могло случиться? } \\
\text { Он тебя обманул }\end{array}$ \\
\hline Он тебя обманул & $\begin{array}{l}\text { горе, жалость; мне искренне жаль тебя } \\
\text { Он тебя обманул }\end{array}$ \\
\hline унизительно (для тебя)
\end{tabular}


высказывание

\begin{tabular}{lll}
\hline Он тебя обманул & ужас; это действительно дурно \\
\hline Он тебя обманул & сожаление; это серьезная потеря/ущерб \\
\hline Он тебя обманул
\end{tabular}

Используемые здесь в качестве примера эмодзи, как и все остальные, не ограничиваются функцией отображения конца изречения; они поливалентны и также могут быть помещены в середину высказывания, таким образом, комментируя, изменяя или заменяя либо одно слово, либо часть предложения. Они также могут предшествовать высказыванию или вводить его.

Описываемая Крыловым «[т]радиционная функция эмодзи передачи эмоционального компонента коммуникации» [Krylov 2017: 50] дополняется контактоустанавливающей и контактоподдерживающей (т.е. фатической) функцией языка. И тут обнаруживается параллель со знаками препинания. Этот процесс изменения очень наглядно иллюстрируется на примере лингвистической репрезентации человеческого смеха на сайте https://buffer.com/ resources/social-media-language (8.04.2020):

The Evolution of Language

"With mirth and laughter let old wrinkles come." - William Shakespeare, $1596-1598$

"Dude, that made me laugh!" - 1995

"Too funny, LOL!" - 2005

$$
\text { “है, }-2015^{4} \text {. }
$$

4 Эволюция языка

«Пусть только с радостью и смехом приходят старые морщины», - Уильям Шекспир, 1596-1598

«Чувак, ты меня рассмешил!», 1995

«Очень смешно, лол», 2005

《हत) 2015.

В статье «Priroda èmodzi» [2016] автор указывает на то, что наблюдается настоящий бум эмодзи и что «многие популярные эмодзи заменили сленговые словечки, появившееся еще очень давно». Согласно этому наблюдению, «[в]злет популярности эмодзи оказался пропорционален уменьшению использования сетевого сленга».

Имеются в виду, между прочим, высокочастотные буквенные аббревиатуры типа ЛОЛ, ROTFL и т.п. 
«Смайлик обычно располагается сразу после высказывания, к которому он относится, либо в конце фразы. Он также может употребляться отдельно как реакция на процитированную фразу» [Zykov 1999]. В последнем случае эмодзи не имеет функции модификации или дополнения высказывания, а заменяет его, потому что говорящий/писатель полностью отказывается от словесного высказывания и использует вместо него графический символ. Получается своего рода «графический язык». В приведенном выше типичном представлении использование смайлика вместо словесного изречения является последним шагом в последовательности синтаксических и лексико-семантических изменений и упрощений. Полное синтаксическое целое с возвышенным лингвистическим, поэтическим стилем сначала становится упрощенной конструкцией предложения с разговорной маркировкой, а затем на следующем этапе синтаксическая полнота отменяется и сводится к своего рода восклицанию, включающему в себя аббревиатуру. Заключительной фазой этого развития является последовательный полный отказ от словесных элементов. В дополнение к формальным и содержательным изменениям следует отметить, что последние этапы развития произошли всего за несколько лет и, таким образом, свидетельствуют о чрезвычайно динамичном развитии языка. Очевидно, что визуальная составляющая становится все важнее и выразительнее в видах нашей повседневной коммуникации.

Следует отметить, что смайлики на самом деле не являются изобретением XX или XXI вв. Так, читатель газеты «Kreisblatt für den Kreis Malmedy», изданной в Санкт-Фите (Сен-Вите, сегодня расположен в немецкоговорящей части Бельгии, а в конце XIX в. еще в прусской провинции Рейна) 2 сентября 1893 г., может насладиться небольшой типографической игрой на странице 3 , «созданной благодаря досугу и хорошему настроению члена гильдии типографов, и напоминающей выражения лица веселого, безразличного и грустного человека» ${ }^{5}$.

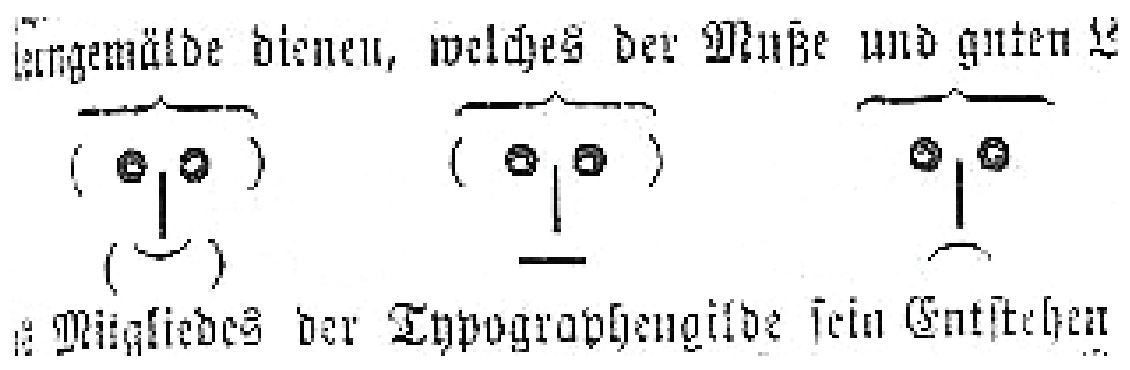

5 «[...] welches der Muße und guten Laune eines Mitglieds der Typographengilde sein Entstehen verdankt, und den Gesichtsausdruck eines Lustigen, eines Gleichgültigen und eines Traurigen zur Anschauung bringt» [«Kreisblatt für den Kreis Malmedy», 2 сентября 1893 г., с. 3]. 
И в художественной литературе встречается немало примеров для игровой комбинации текстуальных и типографских элементов.

Как можно объяснить беспрерывное расширение смайликов, эмотиконов и эмодзи? «Сетевой компьютерный диалект используется в основном для неформального общения членов сети, и поэтому возникла необходимость передачи эмоций и (отчасти) мимики пишущего, что в обычном тексте сделать достаточно сложно; в результате чего появились специфические знаки препинания (т.н. смайлики)» [Zykov 1999]. Обычно первое появление современных смайликов датируется 1982 г. Разные авторы с полным основанием указывают на то, что эти графические элементы, в качестве символослов, вопреки их возможному смысловому содержанию, «привносят в общение игровой элемент» [Babalova, Širobokov 2015: 40]. Стэнфордский лингвист Тайлер Шнобелен добавляет к этому, что «когда дело касается онлайн-переписки, мы ведем себя как дети» [Priroda èmodzi 2016]. К такой визуальной составляющей «можно отнести эвфемистические замены нецензурных выражений на бессмысленные наборы различных символов, например, @\#\$! @\#\$! \# или @\#\$\%^\&» [Babalova, Širobokov 2015: 40]. Такие графические элементы нам уже давно хорошо известны из комиксов, ориентированных прежде всего, но не исключительно, на молодых читателей.

В рамки таких наблюдений вписывается и следующее утверждение:

Для письменной речи характерно частое использование различных видов символослов. Например, слова, образованные по принципу шарад, где использована омонимия разных слов английского и русского языков: - B4 before - до этого, раньше; - F2F — face-to-face — лицом к лицу. Встреча двух юзеров в реальном мире; - 2ю - to уои - адресуется тебе (табл. 1) [Babalova, Širobokov 2015: 40].

Помимо определенного игрового элемента тут играет роль и аспект языковой экономики.

Подобно знакам препинания, с помощью смайликов и эмодзи легче передать невербальный контекст, сопровождающий само сообщение - мимику, жесты и интонацию. За исключением последнего компонента - порядок слов до известной степени может передать интонацию -, в цифровой коммуникации невозможно выразить элементы невербального или паравербального общения. Также подобно знакам препинания, «[э]модзи и неологизмы попали в мейнстрим и укоренились в массовой культуре» [Priroda èmodzi 2016].

К коммуникативному мейнстриму относится и языковая функция выражения эмоций. Новое в этом контексте заключается в том, что в Интернете именно «у знаков препинания появляется новая важная роль - индикаторов эмоций» [Tajnaâ žizn' 2015]. Следующий пример наглядно демонстрирует, 
что, по меньшей мере в определенных ситуациях, общение может обойтись и без вербального контента в строгом понимании:

- Хо-хо???

— Жуть!!!!!!!!!!!!!!!!!!

Что интересно, тот же самый диалог сохраняет свою эмоционально-информационную ценность и при полном отсутствии слов.

$-? ? ?$

— !!!!!!!!!!!!!!!!! [Tajnâ̂ žizn’ 2015]

В приведенном микро-диалоге пунктуационные знаки взяли на себя функцию выражения самого высказывания. Следует сказать, однако, что намного чаще те случаи, где знаки препинания теряют свою функцию или выполняют новую, специфическую для цифровой коммуникации задачу. Это касается, в первую очередь, самого высокочастотного и самого нейтрального в традиционном общении знака - точки в конце предложения. В цифровых каналах она ставится только тогда, когда пишущее лицо хочет придать своему высказыванию определенный резкий тон, в то время как либо нейтральное, либо вежливое или даже любезное высказывание обходится без заключительной точки. Альтернативно расстановке или опущению знаков препинания коммуникант может, например, прибегать к использованию эмодзи, выражающих именно желаемую эмоциональную окраску. Интересно, что такое коммуникативное поведение не фиксировано и не объясняется в учебниках или грамматических пособиях - оно развилось само по себе. Причины всему этому все-таки есть: «Язык просто следует за изменениями в жизни. А жизнь стала быстрой и суматошной» [Тајпаâ žizn' 2015].

Изменения внутри языка касаются и типографских условностей:

Существуют также собственные соглашения о знаках препинания и способах выделения текста. [...] Одно из подобных соглашений заключается в том, что текст, написанный заглавными буквами, интерпретируется как произнесённый ОЧЕНЬ ГРОМКО [Babalova, Širobokov 2015: 41].

Уместно добавить, что слово «соглашение» не имеет в виду письменно зафиксированные, кодифицированные правила и инструкции, но, скорее, коды поведения, которые развивались без воздействия со стороны. Другое правило гласит, что нейтральные высказывания в цифровых каналах не заканчиваются периодом, в то время как в традиционном письменном сообщении период считается наиболее нейтральным знаком препинания (см. выше). Сравним, например, в этом отношении мнение А. Мухатаева: 
«Точка в конце сообщения [...] указывает на скрытый подтекст: грубость, недовольство человека тем, что он только что написал, а также то, что разговор закончен. [...] точка часто выглядит лишней и воспринимается по-другому - особенно если сообщение не сопровождают смайлики, эмодзи или стикеры» [Muhataev 2015: 6]. Вопросы цифрового этикета касаются не только расстановки или опущения знаков препинания, но и их замены другими знаками, имеющими в традиционной коммуникации совсем другую функцию. В Интернете «написанное читают моментально и воспринимают как незаконченный поток. Из-за этого многие предпочитают ставить вместо точек запятые, создавая длинные предложения с эффектом повествования будто вам рассказывают историю живьём» [Muhataev 2015]. Интересно, что автор добавит, что «Интернет адаптирует правила письменного языка под себя, а лингвисты и журналисты играют роль наблюдателей» [Muhataev 2015]. Очевидно, что правила цифрового общения не подлежат никаким законам, но развиваются сами по себе, в соответствии с потребностями коммуникационных каналов и их пользователей.

Помимо традиционных способов выделения текста с помощью пунктуационных знаков развились еще новые возможности:

Кроме того, для подчёркивания значения или выделения того или иного слова его принято заключать в скобки при помощи нетипичных символов. Существует семантическая разница между *выделением как здесь* и *выделением *как *здесь*. В первом случае вся фраза выделяется как единое целое, а во втором выделяется каждое отдельное слово. Подразумевается, что автор высказывания говорит медленно, тщательно выговаривая каждое слово [Babalova, Širobokov 2015: 41] $]^{7}$.

Также в нецифровой письменной коммуникации, например, в немецком языке, особенно в рекламе, в лозунгах и т.п., развилось специфическое использование периода и восклицательного знака, которые используются для того, чтобы отделить друг от друга отдельные слова фразы и тем самым подчеркнуть их особым образом:

${ }^{6}$ Ср., в этом контексте, следующую цитату: «It's a remarkable innovation. The period was one of the first punctuation marks to enter written language as a way to indicate a pause, back when writing was used primarily as a record of (and script for) speech. Over time, as the written word gained autonomy from the spoken word, punctuation became a way to structure a text according to its own unique hierarchy and logic. While punctuation could still be used to create or suggest the rhythms of speech, only the exclamation point and question mark indicated anything like what an orator would call "tone"» [Crair 2013].

7 Бабалова/Широбоков указывают на то, что «[в]стречаются и другие варианты выделения: \такое/, =такое=, /такое/, <такое>,_такое» [Babalova, Širobokov 2015: 41]. 


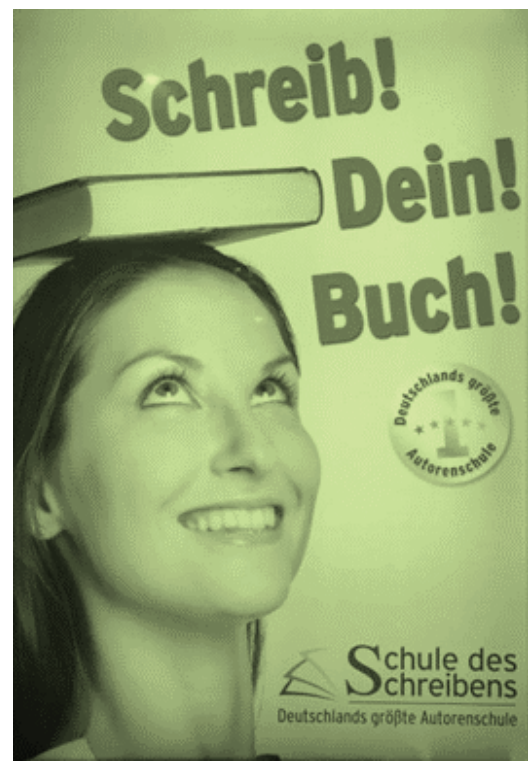

https://www.deutschmeisterei.de/35941-2/; 8.04.2020

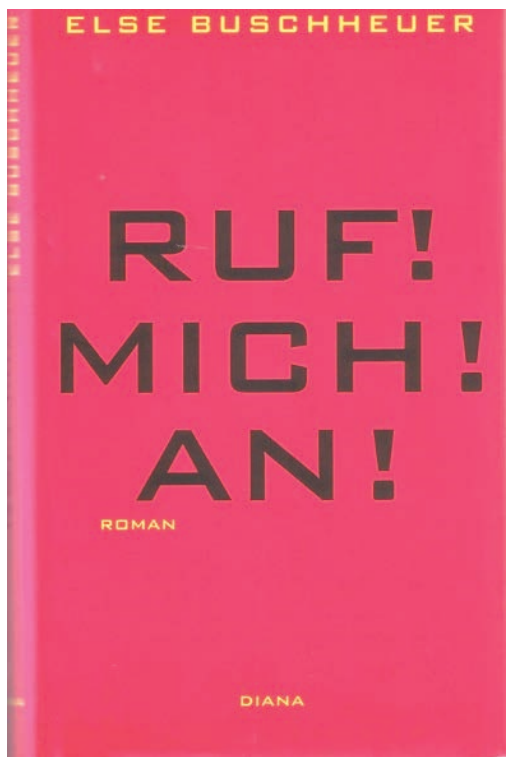

https:/www.kitziblog.de/2017/10/11/ buchtipp-ruf-mich-an-ilse-buschheuer/; 8.04.2020

Повторное употребление восклицательного знака усиливает контент высказывания, увеличивает его убедительность, по сравнению с однократным употреблением в конце предложения: высказывание в большей степени ритмизируется и акцентируется. Подобную приведенным примерам конструкцию с повторяющимися восклицательными знаками (как, например, «Позвони! Мне!») не удалось отметить в русском языке.

Точка в качестве разделителя слов не является феноменом настоящего времени. Мейнхольд [Meinhold 1932: 26], например, рассказывает о еврейских рукописях, в которых точка служила разделителем слов и предложений. Точку также можно использовать вместо запятой в перечислениях. Каждое слово, таким образом, приобретает статус завершенного высказывания и, благодаря измененной интонационной модели, более высокую значимость. Ср. следующий пример: «Люди. Шансы. Будущее.» вместо нейтрального «Люди, шансы, будущее».

Подведем итоги вышесказанному. Нынешняя коммуникация в различных цифровых каналах представляет собой специфическую смесь из черт как письменного, так и устного общения, к которым добавляются некоторые игровые моменты. Все эти составляющие создают новый вид коммуникации, где встречаются элементы не только всех сфер общения, но и, отчасти, получившие новые функции, и где сливаются характеристики устной и письменной коммуникации. 


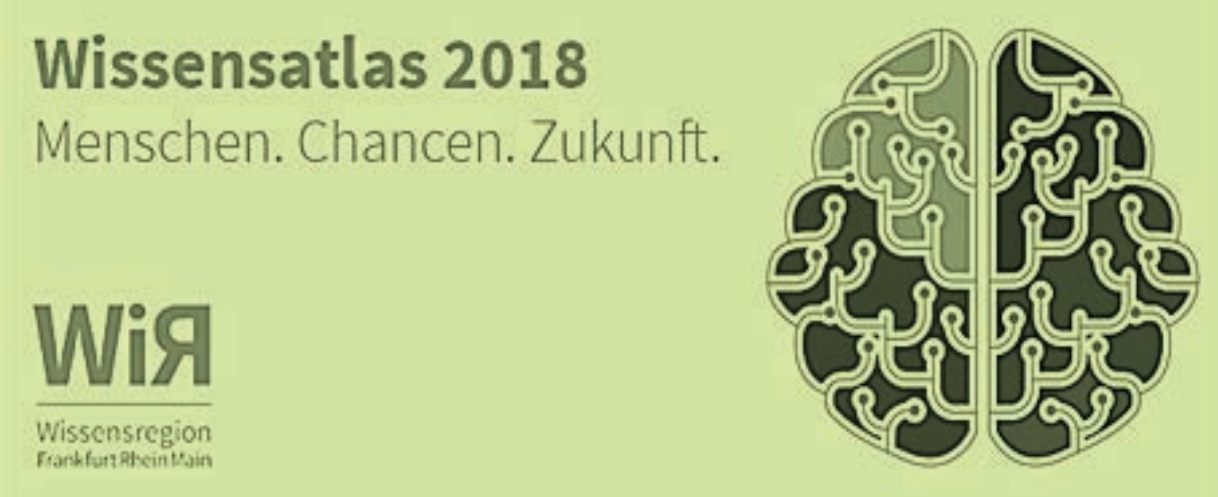

https://www.wissensportal-frankfurtrheinmain.de/; 8.04.2020

В то время, как знаки препинания составляют более или менее замкнутую лингвистическую категорию в размере 10 основных элементов, в которой изменения и добавления проходят весьма редко, число эмодзи беспрерывно и даже бурно возрастает и скоро достигнет общего количества 3000 символов. Вопреки всем языковым реформам, с одной стороны, и всем внеязыковым изменениям, с другой стороны, система знаков препинания осталась относительно стабильной и до сегодняшнего дня отражает фактически все потребности человека сопроводить и, где это нужно, модифицировать значение последовательности графем. Неограниченная, открытая система эмодзи, однако, умеет быстро реагировать как на внутриязыковые, так и на внеязыковые изменения и потребности. Так, появление коронавируса в конце 2019 и начале 2020 гг. наглядно продемонстрировало переменяющееся употребление определенных эмодзи, имеющих отношение к здоровью, болезни и страхам пользователей в связи с пандемией (ср. [Emojipedia 2020]).

Очевидная параллель знаков препинания и эмодзи состоит в том, что и та, и другая знаковая система получили дополнительную функциональную нагрузку, выходящую за рамки первоначальной концепции. Однако, семантика знаков препинания однозначна (что не исключает поливалентности в определенных случаях), в то время как семантика эмодзи нередко характеризуется как диффузная и, тем самым, волей-неволей дающей место для интерпретации.

В цифровом и в нецифровом видах коммуникации правила расстановки пунктуационных знаков функционируют по-разному. Некоторые знаки в чатах, форумах и мессенджерах ведут себя не так, как в традиционной, аналоговой коммуникации. Это касается, например, точки в конце предложения, для расстановки или опущения которой действуют особые закономерности и привычки. В общей сложности можно сказать, что знаки препинания в цифровом общении расстанавливаются намного реже чем в аналоговых видах публикаций, к которым можно отнести и тексты более официального характера, 
опубликованные в Интернете. Причины этому заключаются и в принципе экономии, свойственном многим каналам цифровой коммуникации, и в неофициальном или якобы неофициальном характере общения, а также в том факте, что такое общение доступно для самых широких масс населения, в том числе и для пользователей, обнаруживающих более низкий уровень образования. Аналогично этому наблюдению можно констатировать, что система смайликов, эмотиконов и эмодзи почти исключительно применяется в цифровой коммуникации; употребление таких символов весьма редко в традиционных каналах общения.

Итак, вопреки всем явлениям смешивания письменных, устных и полу-устных видов коммуникации, пунктуационные знаки, с одной стороны, и эмодзи и подобные им символы, с другой стороны, имеют свои специфические этикеты и сферы употребления, что не исключает, как мы видели, явных формальных и смысловых параллелей.

\section{Литература}

Babalova G.G., Širobokov S.N., 2015, Komp'ûternyj sleng, Omskij Naučnyj Vestnik, 3 (139), pp. 38-42.

Crair B., 2013, The Period Is Pissed, https://newrepublic.com/article/115726/period-oursimplest-punctuation-mark-has-become-sign-anger; 5.05.2020.

Emojipedia, 2020, https://emojipedia.org/; 4.05.2020.

Emoji Use in the New Normal, 2020, https://blog.emojipedia.org/emoji-use-in-the-newnormal/; 4.05.2020.

GOST R 51725.17.1-2016, http://docs.cntd.ru/document/1200138355; 8.04.2020.

Krylov Û.V., 2017, Semantika èmodzi v virtual'nom dialoge, Vestnik Omskogo gosudarstvennogo pedagogičeskogo universiteta. Gumanitarnye issledovaniâ, 2 (15), https://cyberleninka.ru/article/n/semantika-emodzi-v-virtualnom-dialoge; 26.04.2020.

Meinhold J., 1932, Einführung in das Alte Testament: Geschichte, Literatur und Religion Israels, Berlin: De Gruyter.

Muhataev A., 2015, Cifrovoj ètiket: Točku možno ne stavit', http://www.lookatme.ru/mag/ how-to/etiquette/214233-etiquette-no-full-stop; 6.05.2020.

Petrov M., 2015, Do poslednej zapâtoj: kak poâvilis'znaki prepinaniâ, https:// theoryandpractice.ru/posts/11531-punctuation; 9.05.2020.

Priroda èmodzi: Priroda èmodzi (emodji), ili kak social'nye seti menâût naše obŝenie?, 2016, https://pgenerator.ru/blog/2016/02/18/priroda-emodzi-emodji-ili-kak-socialnyeseti-menyayut-nashe-obshenie/; 26.04.2020.

Tajnaâ žizn': Tajnaâ žizn'znakov prepinaniâ v èpohu Interneta, 2015, https://www.kaspersky. ru/blog/cyber-slang-peculiarities/9145/; 9.05.2020.

Zykov N., 1999, Kratkij slovar' FIDOvogo dialekta, http://www.lib.ru/ANEKDOTY/ sleng.txt; 16.01.2020. 